\title{
Knowledge management tools of rice technology in Nepal
}

BP Tripathi ${ }^{1}$

\begin{abstract}
Technology plays an important role for enhancing production and productivity. In Nepal, the apex research body, Nepal Agricultural Research council (NARC) is mandated for generating technology whereas Department of Agriculture Extension is responsible for disseminating rice technologies to the farmers' fields through different channels of the system. Different International and National Non-Government Organization (INGOs/NGOs) are also involved in dissemination of rice technologies as well. Although technologies are disseminating however, adoption rate of rice seems to be low. Awareness is an issue to adopt the right technology. Knowledge Management Tools (KMT) followed for rice in Nepal are fact sheets, farmers' field school, printed media, radio, television, toll free services, training and visit, and mini-kit distribution. Therefore, to find out the gap between adoption and disseminating technology, a study on KMT was carried out. Informant survey was launched to collect the data covering four regions of Nepal taking 2 districts in each region during 2010. Mini-kit distribution to the farmers, technologies through farmers' group and training to the farmers were the most effective for transferring rice technologies, which were confirmed by $49(62.9 \%), 46(59.0 \%)$ and $41(52.8 \%)$ interviewed farmers, respectively. Among the electronic media, FM radio and radio were most effective tools for disseminating rice technologies, which were shown by $33(42.3 \%)$ and $23(29.5 \%)$ farmers respectively. Among the printed media, booklet and news paper were most effective for transferring rice technologies as confirmed by $21(27.0 \%)$ and $13(16.7 \%)$ farmers respectively.
\end{abstract}

Key words: Knowledge management tools, rice, print and electronic media

\section{Introduction}

In 2025, according to UN projection, the world population could reach more than 8 billion. Population growth coupled with rising income in developing countries will generate an enormous demand for food, most notably in the nations of Asia, Africa, and Latin America (Adams, R.McC., 1990). By 2025, the growing need of human population will require $25 \%$ more rice (IRRI, 2009). Four essentials (national stability, political commitments, a growing research and extension capacity, and a motivated farming community) have contributed significantly to accelerating the application and diffusion of agricultural research knowledge in enhancing food and agricultural production during the past twenty years (Sadikins, 1990).

${ }^{1}$ IRRI-Nepal Country Office, NARC Building, Singha Durbar Plaza, Kathmandu, Nepal. bhaba.tripathi@gmail.com 
Outdated technologies result in low gains and high losses; and insufficient market knowledge that puts them at an economic disadvantage. "Information is a source of learning" according to $19^{\text {th }}$ century Quaker Minnister William Pollard. "But unless it is organized, processed and available to the right people in a format for decision making, it is a burden, not a benefit" (IRRI, 2009). Many books, magazines, conferences, venders, consultancies, websites, online communications and email lists have been formed around the world to improve the livelihood of farmers, especially in the countries, where a large number of people depend on agriculture (Allee, 2005).

PRISM/WISARD is a wider plate form in the form of website to expose, to share and exchange information on agriculture and allied subjects. PRISM is a shared regional plateform for information of projects (Basnet and Bhatta, 2003). International Rice Research Institute (IRRI) strives to fulfill this gap in knowledge with developed good agricultural practices (GAPs) to ensure that farmers benefit from technologies arising through research (IRRI, 2009). The Irrigated Rice Research Consortium (IRRC) of IRRI has developed a website for GAPs for lowland irrigated rice that can be accessed via the Rice Knowledge Bank (RKB). The site provides practical solution to help rice farmers boost yields, and improve grain quality and production efficiency. Since RKB establishment, the RKB has come a long way. It is now well established as the focal point of IRRI's rice-farming knowledge relevant to farmers and the extension community organizations, universities, the private sector, and farmers' associations.

The different research stations of Nepal Agricultural Research council (NARC) and 75 district-based Agriculture Extension Offices of the Department of Agriculture (DoA are mandated for developing technologies and extending those technologies in the doorsteps of farmer, s respectively. Different public, private and academic institutions have been involved in generating and disseminating improved rice technologies. However, the adoption rate seems to be relatively low. The study focuses on finding out different Knowledge Management Tools (KMT) and their mechanisms/processes in disseminating technologies and findings main gaps in technology transfer.

\section{Materials and methods}

\section{Technology transfer mechanisms/processes/methods}

Technical Working Group (TWG) consisting of NARC, DoA, I/NGOs at District, Regional and Central levels has already been functioning in Nepal. They organize Meetings quarterly at district, regional and Centre levels to review achievements, problems, processes and future planning. In this Meeting, Researchers present their technologies and Extension Workers bring their problems to get feed back for the solution. The TWG Committee recommends for further action for fine tuning the technologies to be disseminated. The Research and Extension linkages in Nepal are presented in Figure 1. 


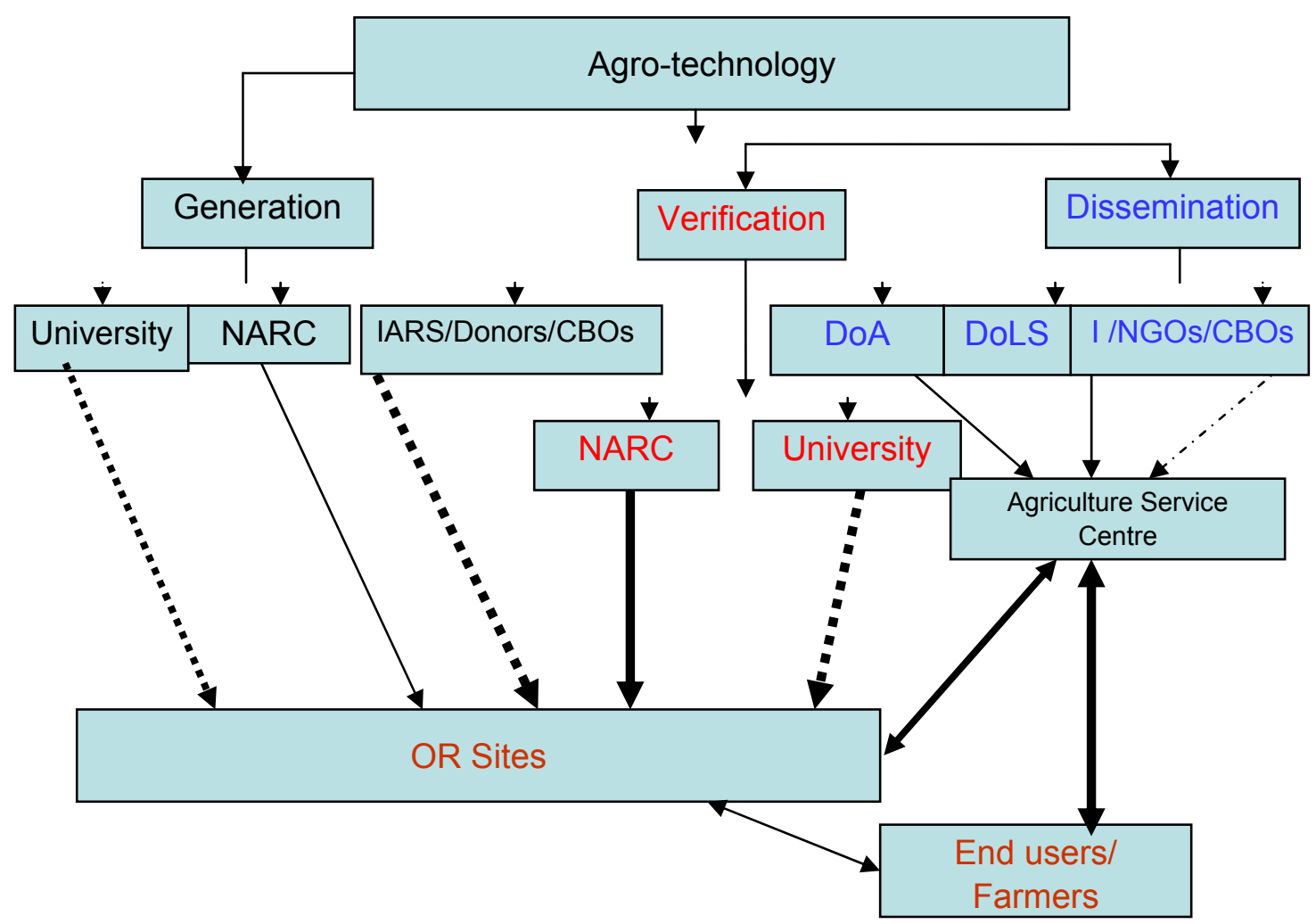

Figure 1. Agro-Technology Development and Transfer Model of Nepal (Paudel, 2007)

In each financial year, there is a system to handover the appropriate Technologies to concerned agencies like DoA and other development agencies. However, it has been felt that adoption of transferred technologies is rather weak and need to be strengthened.

\section{Knowledge management tools (KMTs)}

Some of the Knowledge Management Tools (KMT) used in Nepal for transferring rice technologies are through Radio, FM Radio, Television programs (Visuals, farmers' experience sharing, success stories and new technologies), printed materials in the form of articles, rice fact sheets, booklets, leaflets, posters, graphs and charts), Farmers' Field School, Field Level Demonstrations (Method and Results), Farmers' Field Days in different seasons, distribution and launching of Mini-kits of new varieties, involving farmers in Participatory Variety Selection (PVS), visits of Extension Officers, Technicians and farmers from one district/ region/ country to another district/region/country, crop production competition and awarding farmers at district, region and national level, Farmers' Group Formation and Mobilization for production and income generation, Toll Free Services, Refresher and Regular Trainings to Field-based Extension Staff at different levels (Subject Matter Specialists, Extension Officers, Technicians and farmers). To assess the effectiveness of these Knowledgement Management 
Tools (KMT), four major rice growing Terai (plains) areas covering 2 districts (Sunsari and Saptari in Eastern Region, Bara and Parsa in Central Region) as well as one district each (Rupandehi in Western Region and Banke in Mid-Western Region) were selected for the study. Nineteen farmers in each Eastern and Central Regions as well as twenty each in Western and Mid-Western Regions were randomly selected. A total of 78 farmers were individually interviewed on the different Knowledge Management Tools (KMT) from the above districts of four different regions of Nepal during April-July 2010. Different questionnaires/checklists on the Knowledge Management Tools and their mechanisms and processes of rice technologies dissemination were asked with the individual farmers of the study area. Then, the data were compiled and analyzed.

\section{Results and discussions}

\section{Effect of electronic media}

Electronic media such as FM radio and radio have been popular in Nepal in the recent years. Among the electronic media, FM Radio followed by Radio are most effective for dissemination rice technologies as confirmed by $33(42.3 \%)$ and $23(29.5 \%)$ farmers respectively and the least effective is internet (Figure 1). Farmers of Nepal do not have access of computers and internet in all the villages, where they are living. Secondly, the farmers are not well educated to use the internets in their places. The electronic media only provides information about the new technologies, but do not provide practical knowledge to the farmers. The result of electronic media is supported by Baloch et al. (2006), who reported that radio, although is a powerful medium of communication in the present era of information technology, this medium is less effective as it provides only information not the practical demonstration. However, Sapkota and Shrestha (2008) reported that radio, television and publications have been seen the most facilitating means of awareness of knowledge of technology transfer in Nepal.

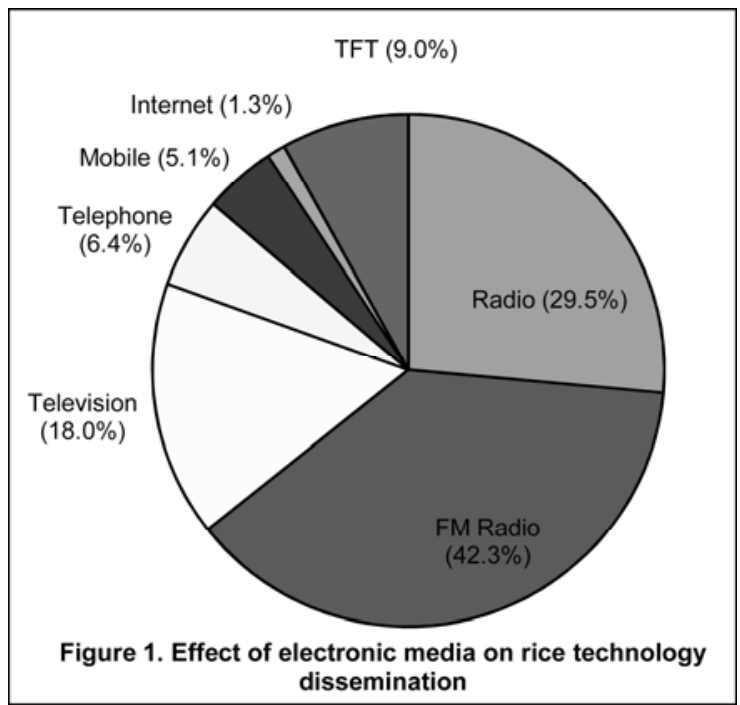




\section{Effect of printed media}

Printed media such as booklet followed by newspaper were less effective as compared to other sources of information for transferring rice technologies as confirmed by $21(27.0 \%)$ and 13 (16.7\%) farmers (Figure 2). This finding was supported by Baloch et al. (2006), who confirmed that the role of pamphlets in providing information and dissemination of improved technologies was recognized by only $8 \%$ of the rice growers in Pakistan. In Nepal, limited printed media in the form of booklet, posters, and pamphlets are produced and distributed to the limited number of farmers. Secondly, most of the farmers are not well educated and do not like to read the printed materials.

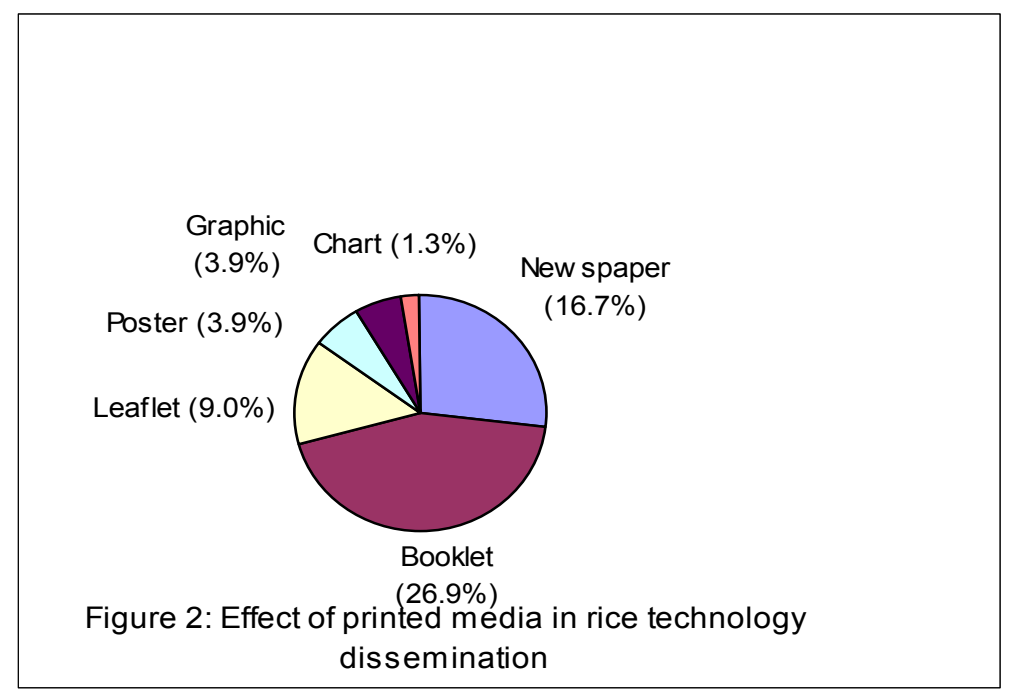

\section{Effect of other than printed and electronic media}

Out of the total 78 surveyed population, $62.9 \%, 59.0 \%$ and $52.8 \%$ rice growers indicated that mini-kit distribution, involvement of group farmers and providing training on improved rice technologies were their preferred source in getting information about technologies as compared to other sources (Figure 3) because farmers practically experience the performances of rice varieties that they get in the form of mini-kits from the different research organizations or agriculture extension offices. When agriculture technologies are provided to the group farmers, they share their practical field experiences among themselves as well as they compete each other for producing more. Regular Training to the farmers on improved agriculture production updates their farming knowledge and capacitate their technical know-how. The above finding was supported by Kamruzzaman et al. (2001), who found that the demonstration farmers of the farming system research sites and multiplication testing sites had less knowledge gap than other farmers. Similar findings were reported by Sapkota and Shrestha (2008), who mentioned that farmers' awareness, demonstration and 
verification in the farmers' field along with the involvement of commercial farmers consisting of private sectors' involvement are the strength of the technology.

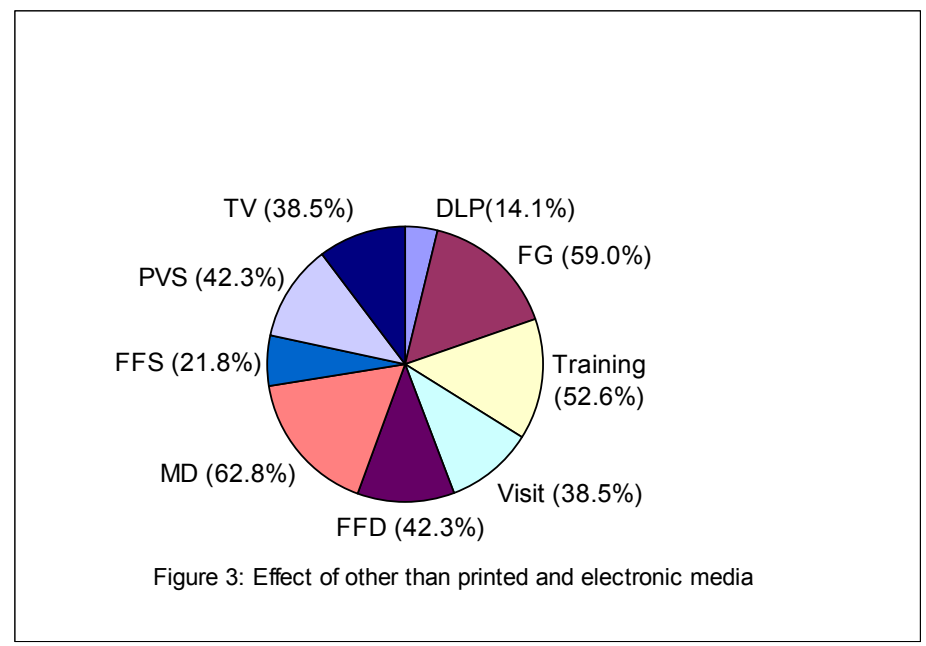

Note: $\mathrm{MD}=$ mini-kit distribution, $\mathrm{FFD}=$ farmers' field days, $\mathrm{FG}=$ farmers' group, $\mathrm{DLP}=$ district level program, $\mathrm{TV}=$ television, $\mathrm{PVS}=$ participatory varietal selection, $\mathrm{FFS}=$ farmers' field school.

\section{Gaps of technology transfer}

All the generated technologies do not reach to the farmers because there is lack of mechanisms/processes of technology transfer. Package of practices of generated technologies should be prepared by the Researchers in simple Nepali language and it should be widely circulated to the farmers' door-steps by extension workers. There should be a strong mechanism of monitoring and evaluation for transferring and evaluating of impact of these technologies. Scientists, who generate the technologies, should be involved in Training to the Subject Matter Specialists (SMS) and Extension Workers for providing new scientific knowledge. Then, SMS and Extension Workers as Resource Persons will provide training to the farmers so that new technologies will reach to the farmers.

\section{Conclusions}

Dissemination of rice technologies are most effective through the distribution of Mini-kits, technologies providing through farmers' groups, regular training to the farmers as well as use of FM radio, radio and organizing farmers' field days during the rice growing season, while internet, charts and posters are the least effective in the study area because farmers of Nepal do not have access of computers as well as literacy rate is low and do not understand the importance of charts and graphs. Availability of inputs (fertilizers, insecticides and pesticides, irrigations, farm tools and machineries) in time are required to adopt the rice technologies. 


\section{References}

Adams, RMcC. 1990. Sharing Innovation: Global Perspectives on Food, Agriculture, and Rural Development (editor: Neil G)

Allee, V. 2005. The knowledge Evolution and The Future of Knowledge. http://www.icimo.org/ home/page.php? $p=i k m$

Baloch, MS, G Hassan and M Zubair. 2006. Role of information sources, extension services and agricultural credit towards rice production in Dera Ismail Khan, Pakistan. SAARC Jn. of Agric. 4:213-220: 2006.

Basnet, BMS and KR Bhatta. 2003. Country Progress Report on PRISM. Nepal Agricultural Research Council (NARC), Kathmandu, Nepal.

IRRI (International rice research institutes). 2009. Annual Report of IRRI. GAPs fill gap. Los Banos, Laguna, Philippines pp 23.

Kamruzzaman, MSM, Fakhrul Islam, MAA Begum, SMA Shiblee, MG Kibria and SK Ray. 2001. Adoption level of wheat technology and the growers' knowledge gap in Bangladesh. Pak. J Bio. Sci. 4: 1-6.

MoAC (Ministry of agriculture and Cooperative). 2009. Statistical information on Nepalese Agriculture 2008/2009. Government of Nepal, Ministry of Agriculture and Co-operatives, AgriBusiness Promotion and Statistics Division. Singha Durbar, Kathmandu. Nepal.

Paudel, MN, RP Upreti, and R Khadka. 2007. Up-scaling of agro-technology: A concept pf participatory outreach research in Nepal. Proceedings of the $8^{\text {th }}$ Nationaal Outreach Workshop held in Khumaltar, Lalitpur, Nepal from 19-20 June 2007, pp 1-9.

Sadikin, SW. 1990. Sharing Innovation: Global Perspective on Food Agriculture and Rural Development. In: The Diffusion of Agricultural Research Knowledge and Advances in Rice Production in Indonesia (Pp106).

Sapkota, S and B Shrestha. 2008. The development and agriculture technology transfer in Asia: A case of Nepal. Paper presented in $3^{\text {rd }}$ SAS-Nepal convention on August 27-29, 2008. 